\title{
The Analysis of the Van-Ercis Earthquake, October 23, 2011 Turkey, for the Transportation Systems in the Region
}

\author{
Hakan Aslan \\ Department of Civil Engineering, Division of Transportation, Sakarya University, Adapazarı, Turkey \\ Email: haslan@sakarya.edu.tr
}

Received September 18, 2013; revised October 20, 2013; accepted November 4, 2013

Copyright (c) 2013 Hakan Aslan. This is an open access article distributed under the Creative Commons Attribution License, which permits unrestricted use, distribution, and reproduction in any medium, provided the original work is properly cited.

\begin{abstract}
This paper investigates the effect of the Van-Ercis, Turkey, $\left(\mathrm{M}_{\mathrm{w}}\right.$ : 7.2) earthquake occurring on 23rd of October, 2011 on the transportation networks in the region. The basic incentive for this research is to conceptualise the reliability and performance of the networks after the earthquake through the operational and topological analysis of the system. The demand and composition of the traffic along with the behaviour of the pedestrians were taken into account to evaluate the performance of the networks. In addition, the general structure of the cities and towns, as far as planning is concerned, is also paid attention and regarded as one of the main elements for the appraisal. The outcomes obtained are thought very important to be guidance for the expected Istanbul earthquake in the near future.
\end{abstract}

Keywords: Earthquake Hazards; Functionality and Reliability of Transportation Networks; Degraded Road Networks

\section{Introduction}

The investigation of transportation networks under the possible effect of natural disasters, such as earthquakes, floods, hurricanes etc., became more important after the Kobe earthquake in Japan in 1995. The basic motivation of these researches is to investigate the reliability and durability of the road networks from the perspective of infrastructure planning and traffic management when some of the components, such as links, of the system are partly closed to traffic with reduced capacity or completely out of use resulting in degraded networks.

Nicholson and Du (1997) proposed an integrated equilibrium model for the networks with long term capacity degradation to allow the traffic flow to adjust itself and move towards a new equilibrium situation [1]. The proposed model is a multi-modal network in the sense that the disaster will not necessarily affect all the transportation modes equally. The model mainly assesses the socioeconomic impacts of road networks under degradation and produces a unique equilibrium solution when a standard concave programming algorithm is used.

Asakura (1998) developed an approximation algorithm for nondeterministic network states as the probability of the failure of a link in the system cannot be precisely determined due to the nature of the earthquake or any other type of disasters [2]. The algorithm investigated the performance of the network through possible network states in terms of the stochastic travel time of an OD pair given in the network. The comparison of generated travel time in a degraded road network considering every combination of the link failures to normal network state is based on the reliability measure defined as the probability of whether the ratio of the travel times obtained from both degraded and normal network states remain within a predetermined acceptable level. The proposed algorithm converges to the exact expected value through upper and lower bounds of reliability measure by employing the most probable state vectors reflecting optimistic and pessimistic expectation of the operated/failure function, respectively.

Kiremidjian et al. (2007) proposed a method for the performance evaluation of a highway transportation system based on the expected loss from damage to bridges and resulting travel times [3]. The method analysed the network by assuming both the travel demand is fixed and variable after earthquake. Risk assessment of transportation system was based on the consideration of both direct cost of the damage and the costs resulting from time de- 
lays in the degraded system. The evaluation of the travel times for all O-D pairs in the system was carried out by using the commercial software EMME/2. The study confirmed the fact that the total vehicle hours increased for the post-earthquake state even the demand in the system is supposed to be the same with the normal network. The variable travel demand model on the other hand, produced decreased vehicle travel hours as the model assigned fewer trips to the system.

Samadzadegan and Zarrinpanjeh (2008) suggested a pre-event digital vector map and post-event high resolution satellite imagery usage to design and assess the damages to the road networks [4].

Shoji and Toyota (2012) analysed the functionality of road networks over which the restoration process of lifeline systems is carried out [5].

As having huge potential of major earthquakes, Turkey faces high probability of devastating earthquakes in the near future. The one being expected to hit the Marmara region where Istanbul is located seems to be the most important with the possible magnitude around $\mathrm{M}_{\mathrm{w}}$ : 7.0 and is thought to have a significant effect on the daily life of the people causing possibly many of them to be killed and the general economy of the country. This is simply due to the fact that the population density and industrial activity in the region represents the highest level for the country.

This paper investigates the technical points of the Van-Ercis earthquake with regard to transportation problems, assesses the network topology and proposes some likely countermeasures to be taken to relieve the adverse effects of the earthquakes by bearing in mind the planning characteristics of the cities in Turkey.

\section{The Transportation Network Performance of City of Van}

The earthquake which hit the southern part of Turkey on 23rd of October, 2011 and affected Van, Igdır, Agrı, Bitlis, Kars, Batman, Siirt, Hakkari, Erzurum, Sanlıurfa, Mardin Mus, Diyarbakır and Northern Iraq had a magnitude of 7.2 Riechter Scale (United States Geological Survey, Kandilli Observatory and Earthquake Research Institute). This earthquake is one of the top three earthquakes along with Kocaeli, $M_{w} 7.6$ in 1999 and Duzce, $M_{w} 7.1$ in 1999, and among the first ten strongest for the last 110 years in terms of moment magnitude. According to official figures, 604 and 2000 people lost their lives and wounded, respectively. The number of people rescued from the rubbles is given as 222 .

Although there was not any problem to arrive Van, the most affected city in the region, by plane, some one-hour delays were reported due to the restriction on parking facilities at the airport during the first couple of days after the disaster. In general, however, it should be stated that the role of Van Ferit Melen Airport was vital for the transportation of the rescue teams and emergency materials from both Turkey and all over the world to the city.

As the destructive effect of the earthquake in the Van city centre was limited and the number of buildings collapsed was just a few, the city transportation network system performed its function without significant decrease in its capacity. This provided an efficient transportation environment to reach the places where people were in urgent need. The transportation infrastructure interms of both roads and traffic management applications, such as traffic signals, was functional and traffic flows were quite running. Figure 1 illustrates the functionality of the transportation network at the heart of the city of Van.

The relative high number of the people left the city due to the psychological reasons after the earthquake caused the demand to decrease significantly by having positive effect on the quality of the city transportation system. The main form of the public transportation, paratransit systems, performed its function and there was not any degradation on service quality.

The state highways connecting Van-Muradiye, Muradiye-Caldiran, Caldiran-Ercis, Ercis-Adilcevaz, Adilcevaz-Ahlat, Ahlat-Tatvan, Tatvan-Edremit, Edremit-Van were not directly affected by the earthquake, and there was not any decrease in terms of the level of service apart from those caused by routine maintenance and construction works. Although some minor cracks caused by the faulting mechanism were determined on the ErcisVan state highway, located very close to the earthquake epicentre, the required repairs were done quite swiftly and effectively so that no major negative impact experienced by the traffic. Figure 2 clarifies the effect of fault on the land and state highway.

As for village roads; Van-Alakoy road was determined as the one physically affected by the fault. Nevertheless, as the cracks were repaired quite rapidly, the traffic flow and connection were not affected. The Figure 3 gives an idea about the size of the cracks on the road and their repairs providing smooth traffic flow.

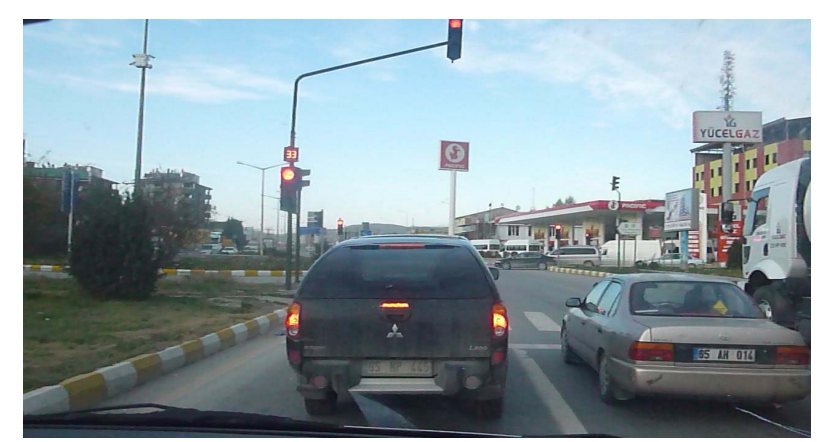

Figure 1. Signalised intersection between the airport and the Van city centre after earthquake. 


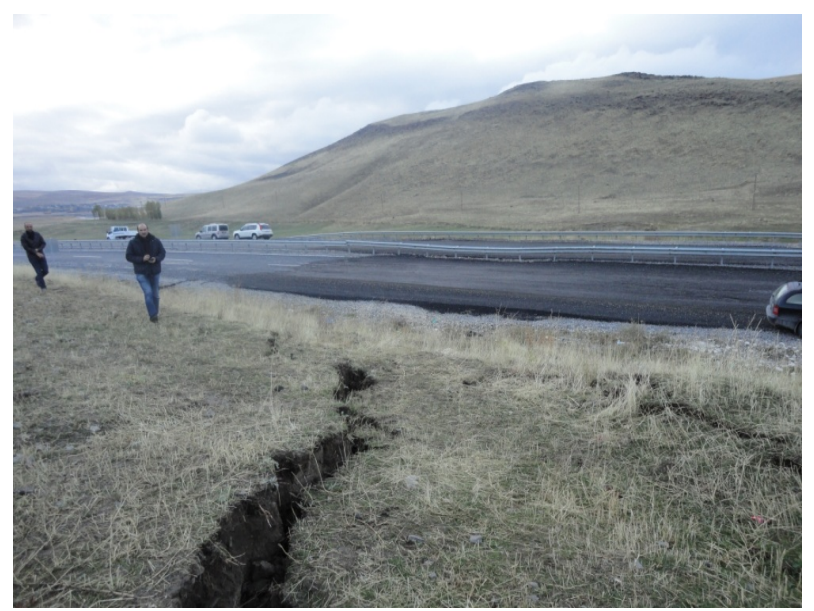

Figure 2. The effect of fault mechanism on Van-Ercis state road and its repair.
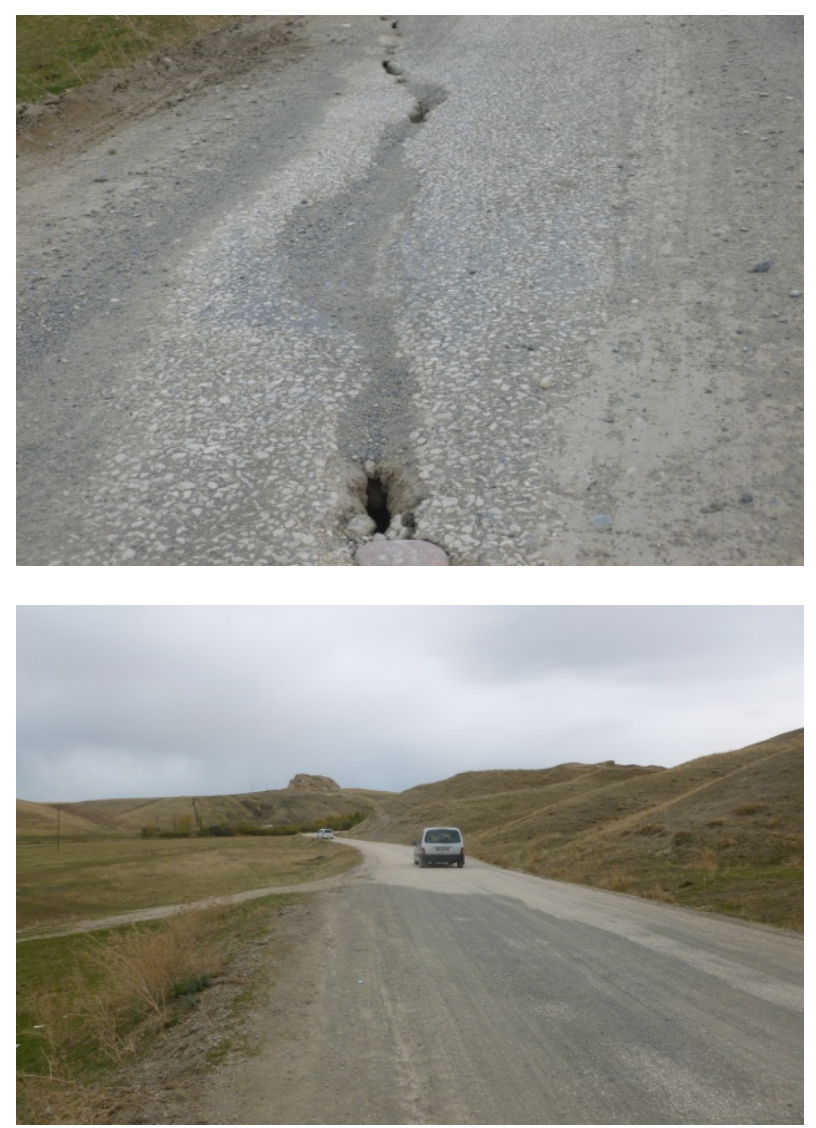

Figure 3. The cracks and repaired road sections on VanAlakoy village road.

The effect of the earthquake being local on a few points in the region along with quick and efficient responses should not be deceptive and not to cause the underestimation of the requirement of the enough human sources, mechanical equipment stock as well as taking the measures of the maintenance work before the earthquake for the transportation systems prone to high scale earthquake impact.

Having this size of earthquake in major cities like Istanbul may result in significant cracks causing the loss of continuity of roadway and highway surface. As a result, there might be major connectivity problems along the network preventing the people reaching and leaving the highly affected areas. The connectivity plays very important role to rescue people from the rubbles and take them to the hospitals in the vicinity at the earliest time possible. The infrastructure must be kept as strong and robust as possible to minimise this adverse outcomes stemming from the cracks to be occurred as a result of strong earthquakes. The major intersection points may be regarded as the key locations with this regard and utmost effort should be paid to get the minimal connectivity problems in case of a strong earthquake.

\section{The Analysis of the Effects of the Earthquake on Ercis Network System}

The district of Ercis where the highest destructive effect of disaster was observed became the mostly affected residential area with regard to transportation network performance. Although the ring road, Figure 4, passing the outside of Ercis and connecting the cities of Van and Agrı was not affected, central transportation system of the town was badly deteriorated.

The traffic on the main arteries of the town; Zeylan, Inonu, Cinarli, Emniyet and Ataturk Avenues, were disrupted due to the partly closures caused by the collapsed buildings on both sides of the roads. Figure 5 demonstrates the main arteries of Ercis town centre.

The average travel speed is measured about $15 \mathrm{~km} / \mathrm{h}$ (around $10 \mathrm{mph}$ ) at the town centre. The reason behind this low speed is attributed toon the one hand the capacity reduction of the roads, on the other hand the insufficiency for the applied traffic management and arrangement techniquesalong with the disobedience of the drivers and pedestrians to the traffic rules. The effective and efficient arrangements of horizontal and vertical traffic signs within a short period of time would result in a better traffic movement in terms of the physical capacity usage of the road network.

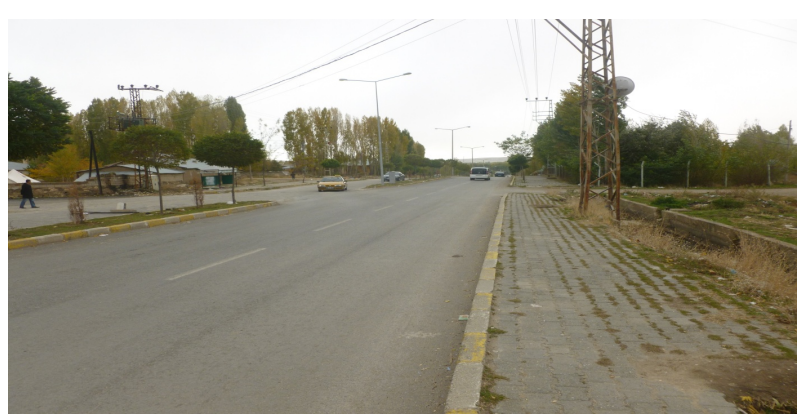

Figure 4. The Ercis ring-road after the earthquake. 


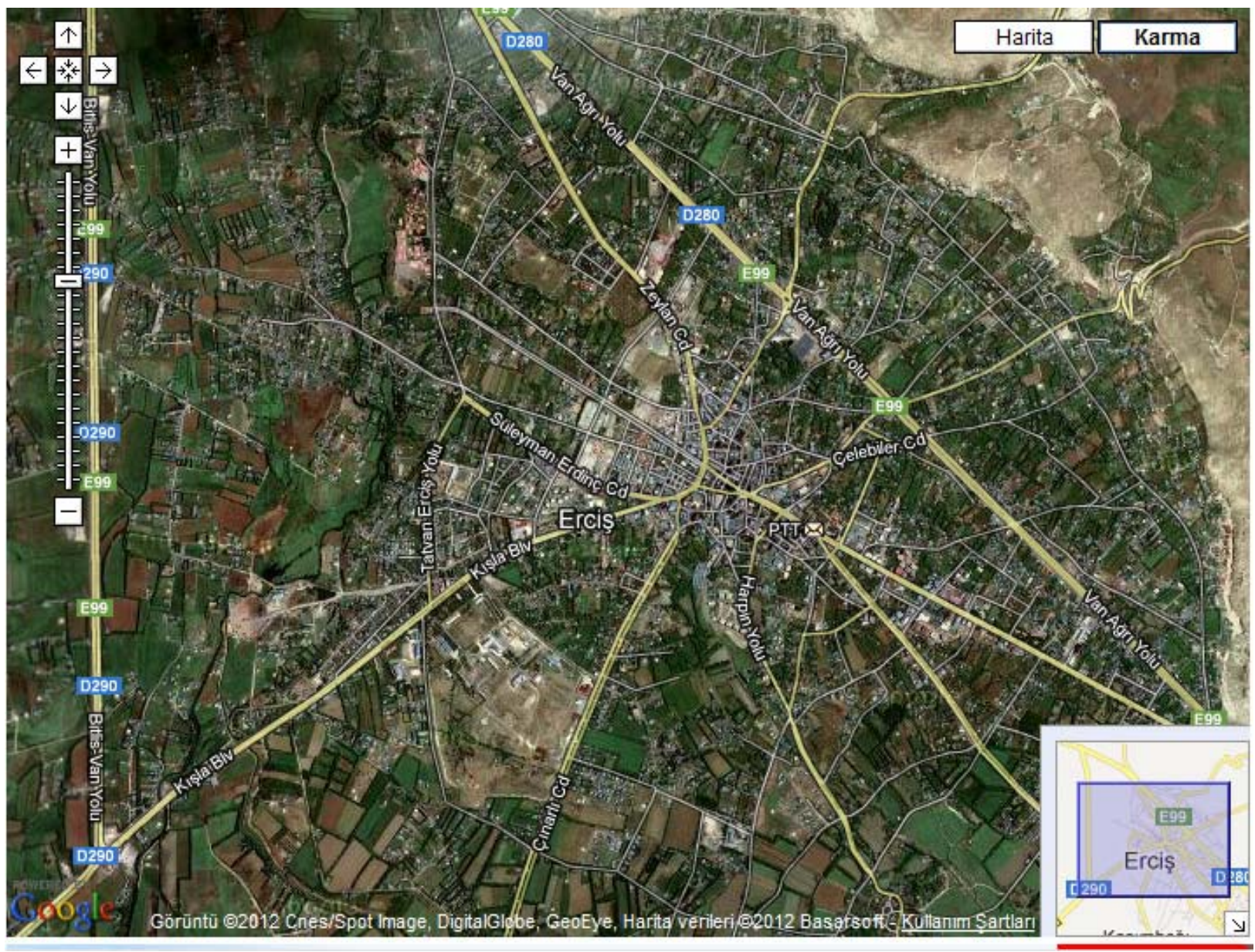

Figure 5. Ercis town centre and transportation network.

Figure 6 next page illustrates the chaotic nature of the traffic in Ercis town centre explaining the slow travel speeds.

Since the daily needs of the people, such as cooked food, water, blankets etc., are provided on the roads of the town by the specially designed lorries, there were long queues at the town centre blocking the through traffic to a degree causing slower traffic on some parts of the network.

As the earth-movers used to remove the rubbles had to use the network unlike from the usual daily traffic conditions, the concomitant effect of this usage on the average travel speed was unavoidable. This effect comes from both the slow speed and the size of these types of vehicles. It has been observed that the capacity of the roads is heavily occupied by these earth-movers on every time of the day.

Since the alternative road sections were not available for the through traffic, there occurred long queues right behind of these vehicles with even more reduced average travel speed of $15 \mathrm{~km} / \mathrm{h}$ along Zeylan street. It has been advised to the local authorities that the development plan for the topology of the transportation network in the Ercis town centre must consider this point and alternate connections must be available for the town centre. The radial network system seemed to be quite effective and feasible with this regard for the future planning of the town centre in Ercis providing alternate connections between Zeylan street and the ring road.

Figure 7 clearly shows the effect of non-daily traffic vehicles and movements on the traffic after earthquake.

The present bridges, viaducts and tunnels on the prementioned alignments of highways in the region performed their functions and none of them has been reported being totally or partly collapsed causing signifycant accessibility problem. Figure 8 illustrates the bridge on the road between Van and Alakoy, one of the villages mostly affected by earthquake.

As being the key elements of whole transportation network in terms of providing essential connectivity, bridges and viaducts are extremely important road sections. Thus they have to be constructed carefully and strongly by paying attention on their role and inevitable importance in case of an earthquake. 


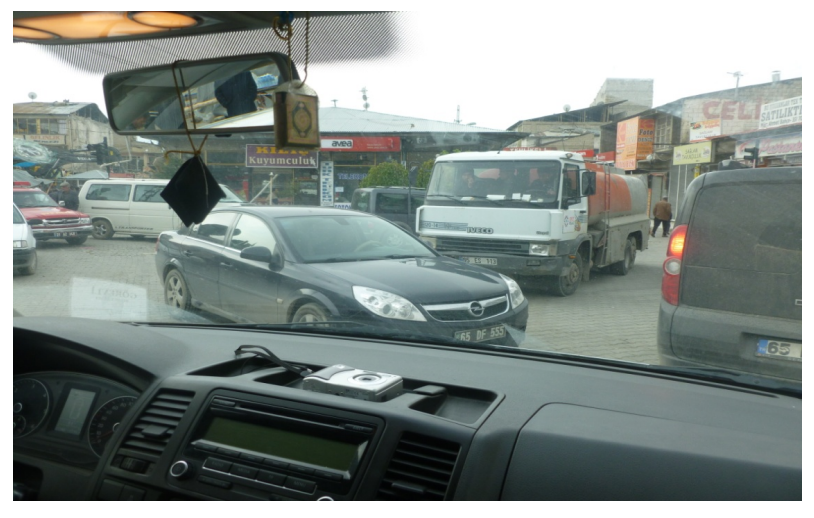

Figure 6. The chaotic structure of the central traffic flow at the town of Ercis.

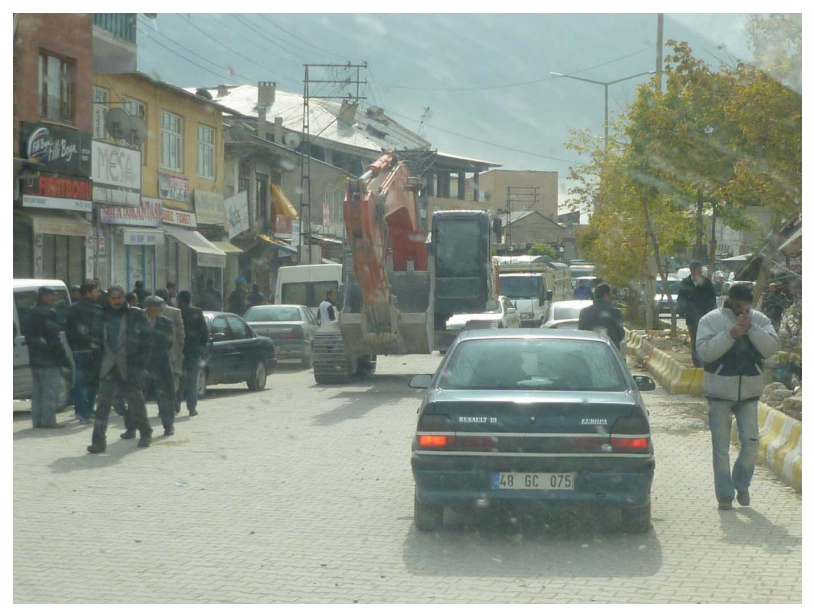

Figure 7. The effect of earth-movers on Ercis town centre traffic.

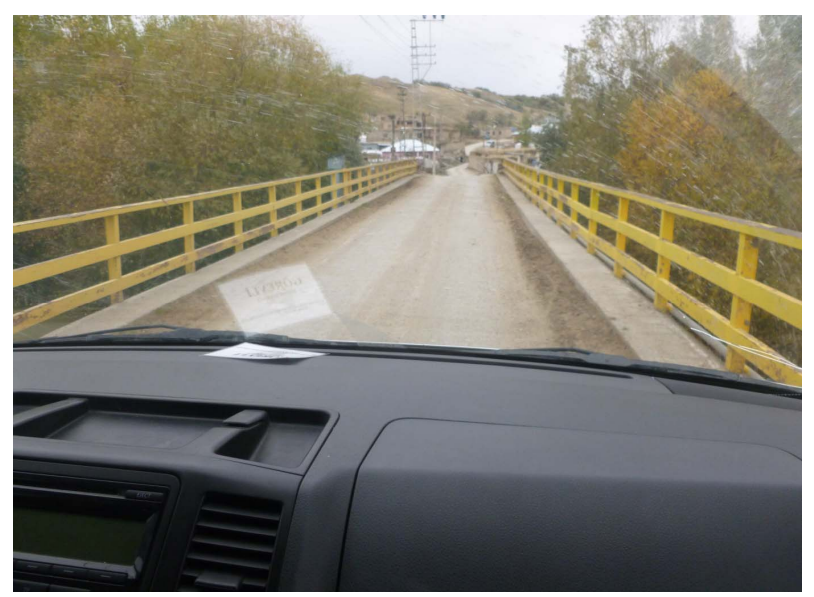

Figure 8. A functional bridge just before Alakoy.

\section{The Effect of City Planning and Collapsed Buildings on the Traffic Flow}

It was fortunate that there were only a few buildings collapsed blocking the main arteries to a certain extent by not causing in total connectivity failure. In addition, al- most every main artery was accessible through the available side roads providing a passage for the emergency and health service vehicles to take the required action on time. If the destructive effect of the earthquake had been more severe with much more building falling down, the topological characteristics of the transportation network would not have lessened the negative aspects of the outcomes to be experienced. The town centre, where the governmental offices are located to be used for managing the earthquake, was reachable only via Zeylan street. The total closure of this single artery in the future earthquakes means that the management of the earthquake would be much less efficient in terms of both providing the basic life saving equipments to the people and the coordination of the organisations being in the region to help the residents.

Another important point to be taken into account is related with the development plan of the cities and towns especially with the high-density population. The required distance between the edge of the roads and the buildings with regard to the height of those buildings should be determined in a way that the collapse of the buildings would not cause the entire even partly closures, reducing the capacity significantly, of the roads to be used for effective response in case of earthquake. The minimisation of this negative effect for the main arteries plays a vital role for the performance of the transportation network for the future and stronger earthquakes in the region. On some main roads in Ercis, it was observed that residential buildings started just the end side of the main roads without even pavement sections for the pedestrian usage. The collapse of such buildings had direct impact on the partly closure of the vital roads.

Figure 9 illustrates the effect of the collapsed buildings on the main arteries in Ercis.

Another striking point observed was the lack of parking spaces for the private cars both day time and night time. It has been detected that the number of cars squashed under the rubbles of the buildings is quite numerous. This fact must urge the local authorities to determine and provide safe parking areas and facilities for the people living in Ercis. This would surely minimise the cost of the car owners and insurance companies along with providing excellent opportunity to use the parking areas as the accommodation of the people in the tent cities. Day-time usage of the parking areas as part of the park-and-ride traffic would result in the demand reduction revealing the traffic congestion in the town centre. According to the traffic survey conducted by us the required parking area for the day time is for 5000 vehicles in terms of car equivalent around the town centre.

Figure 10 might give an idea about the collapsed buildings and trapped vehicles under the rubbles.

In order to maximise the mobility of those vehicles, 

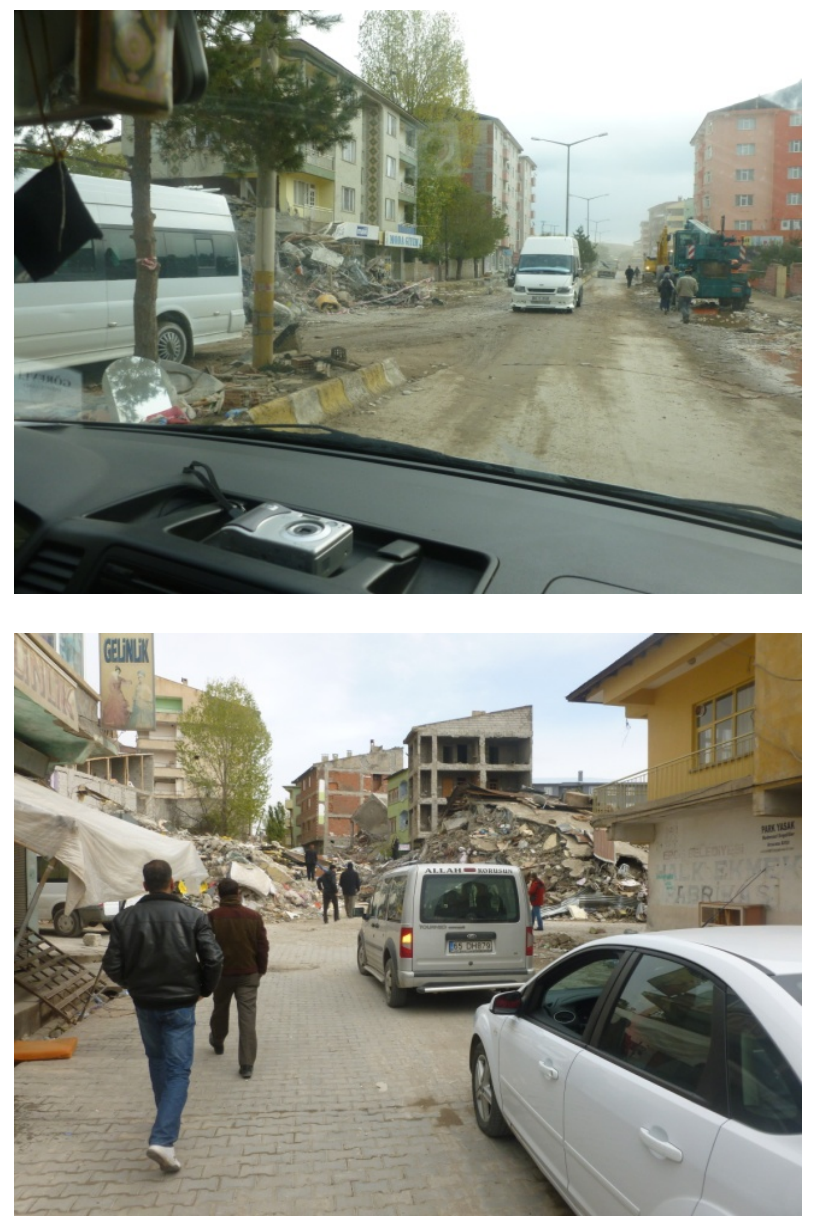

Figure 9. The effect of collapsed buildings on the town centre traffic in Ercis.

especially the heavy ones, carrying aid materials, the traffic assignment and parking locations of these vehicle must be predetermined, which was not the case in Ercis. This would certainly provide the fastest arrival of these vehicles to the points where they are needed by minimising their possible adverse effects to the daily traffic on the network. The fact that around 150 articulated lorries demanded to use the network daily in the first three weeks to provide the urgent needs for the people of Ercis with the population of 90,000 caused the network to be much busier and slower than the pre-earthquake state. The size and number of these vehicles were beyond the capacity and physical structure of the town network for a smooth and efficient traffic flow. It is quite clear that this becomes much more important for a possible earthquake affecting major cities with a population more than couple of millions.

The present law forces the compulsory construction of the parking areas under the apartments through the basement. This provides both parking facilities for the vehicles and stronger buildings against earthquakes. However, the investigation of this point in Ercis town
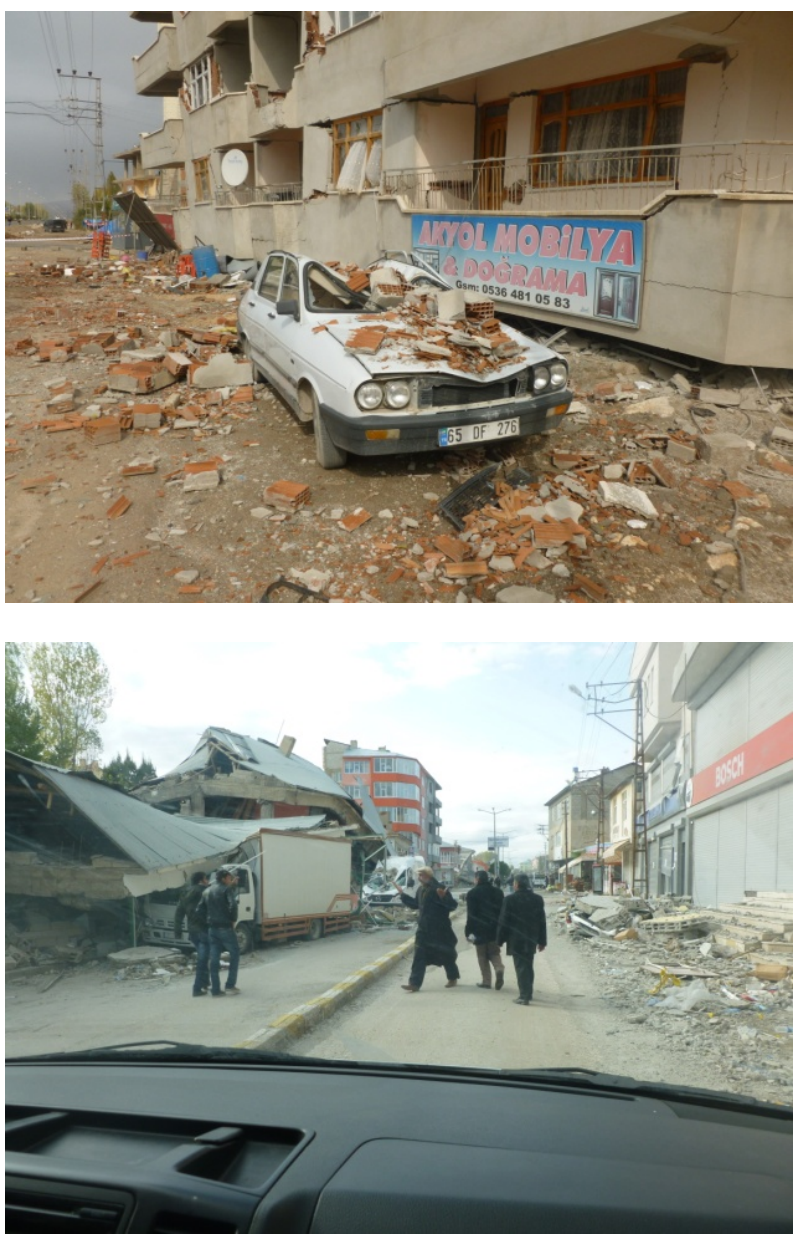

Figure 10. Vehicles trapped under the collapsed buildings.

centre revealed the fact that even major buildings did not have such facilities. The importance of this emphasised during the technical meetings with the local authorities and they were asked to show zero tolerance for the non-construction of these basements as the construction would increase the cost of the building to some extent.

\section{Pedestrian Movements}

Another important traffic element that should be mentioned is the movement of the pedestrians. The disorganized nature of the traffic right after the earthquake influenced the pedestrians as well. The observed pattern of the pedestrians in Ercis town centre was quite disorderly without obeying the basic traffic rules, including disobedience to traffic lights, walking on the pavements, sudden crossings the roads, etc. Although this can be tolerable to some extent considering the slow moving nature of the traffic and the psychological situation of the people right after the disaster, all measures should be taken to prevent this traffic pattern to be the daily habitual after the earthquake's adverse effects disappear in the long term. 


\section{Discussions and Conclusions}

The problems caused by earthquake should be dealt with through holistic approach as it is related with many aspects of the daily life. Security, health services, geotechnical engineering, structural engineering, Emergency Aid and Rescuing, infrastructure of life-lines, transportation etc. are some of the parts of all these multi-categorised nature of the earthquake. All these sub-elements point out the effective coordination between the official and private organisations for the risk and hazard analysis of the earthquake.

As far as the transportation system and risk analysis are concerned, the connectivity, travel time and capacity reliability evaluations with regard to different scenarios must be done well before the earthquake hits and the strategies should be developed in terms of the worst case scenario. This analysis would not only relieve the transportation system and traffic flow but will also provide an efficient rescuing activity along with the fact that the aid materials reach their required destinations efficiently after the earthquake.

These studies have not been done in the region thoroughly and the cities and towns were not ready for the devastating effects of the earthquakes. Luckily, the effect of the earthquake was not proportional to the magnitude of it. If the effect had been bigger, the result that has been faced with would not have been as moderate as it happened.

The optimal locations of the rescue centres are another important problem in the field of transportation to be solved. This is vital as far as the prompt actions to be taken to save the lives.

The realistic evaluation of the transportation system as a whole in the region revealed the following points to be considered to lessen the current and possible future effect of the earthquakes in the region and as a whole.

- The network topology must be analysed to make sure that maximum accessibility is available in case of earthquake for the future planning of the cities and towns. The vital official organisations are to be located to minimise the adverse effects of the present topology's accessibility limitations. The determination of these locations is an optimality problem to be solved.

- The constructional arrangements of the buildings especially on the major arteries should be done to minimise the possible road closures in case of collapse.

- The parking facilities should be analysed and required capacity must be provided at the feasible locations of the cities and towns by considering the needs of the aid convoys, too, as an element in emergency transportation planning in long-term planning.

- Horizontal and vertical traffic signs must be repaired and kept operational right after the earthquake to provide a safe and efficient traffic environment for both vehicles and pedestrians.

- The availability of the public transportation system plays an extremely important role after the earthquake for the mobility of the population in an effort to reduce the earthquake effect on the mobility. Hence, it is vital that the infrastructures of the public transporttation systems are functioning. The provision of this results in orderly and efficient traffic system on the network by encouraging people using public transportation systems rather than being on the roads without obeying the traffic rules with their private cars.

- In order to give the impression to the people that the traffic system is still under control and operated by professionals even after the earthquake, these officials must be ready for the post-earthquake network management through proper training sessions. The contents of these sessions are to be determined by taking into account of the plants and paths of the public transportation, general behaviour of the public, physical structure of the transportation network and possible magnitude of the earthquake itself.

As the major transportation corridor to Iran is in this region, the possible future earthquakes might affect this highway corridor inextricably tied to transportation network causing significant trade loss. The required maintenance works must be properly scheduled and the plants must be kept ready all the time to minimise the adverse effects of the earthquake in this sense.

\section{REFERENCES}

[1] Z. P. Du and A. Nicholson, "Degradable Transportation Systems: Sensitivity and Reliability Analysis,” Transportation Research Part B, Vol. 31, No. 3, 1997, pp. 225-237.

[2] Y. Asakura, "Reliability Measures of an Origin and Destination Pair in a Deteriorated Road Network with Variable Flows," Selected Proceedings of the 4th EURO Transportation Meeting, 1999, pp. 273-287.

[3] A. Kiremidjan, J. Moore, Y. Y. Fan, O. Yazlalı, N. Basoz and M. Williams, "Seismic Risk Assessment of Transportation Network Systems,” Journal of Earthquake Engineering, Vol. 11, 2007, pp. 371-382.

[4] F. Samadzadegan and N. Zarrinpanjeh, "Earthquake Destruction Assessment of Urban Roads Network Using Satellite Imagery and Fuzzy Inference Systems,” The International Archives of the Photogrammetry, Remote Sensing and Spatial Information Sciences, Vol. 37, Part B8, Beijing, 2008, pp. 409-414.

[5] G. Shoji and A. Toyota, "Function of Emergency Road Networks during the Post-Earthquake Process of Lifeline Systems Restoration,” Journal of Disaster Research, Vol. 7, No. 2, 2012, pp. 173-182. 